\title{
Effects of Electromagnetic Fields due to High Voltage Transmission Lines on Detonator Firing Circuits
}

\author{
W.F.M. Fernando, W.D.A.S. Rodrigo and W.D.A.S. Wijayapala
}

\begin{abstract}
High voltage AC transmission is the common mode adopted in transmitting bulk electrical power from one station to the other. Overhead high voltage (HV) transmission lines which carry bulk electric power emanate electric and magnetic fields which could influence the devices in their proximity. Detonator is one such electro explosive device (EED) that is susceptible to electromagnetic coupling when placed in proximity to the transmission lines which in turn could cause inadvertent misfires.
\end{abstract}

This paper focuses on the computational modeling of electric and magnetic fields around overhead high voltage transmission lines at various voltage levels and line configurations, starting from fundamental electromagnetic principles and the verification of those models by field measurements. MATLAB software was used in modeling the field profiles and the developed model is capable of accommodating any configuration with any combination of conductors. The overhead transmission line parameters used in this paper are from the present line configurations practiced in Sri Lanka. For the validation of the model, electric and magnetic fields of transmission lines were measured in the field and compared with the modeled values.

Using the developed electric and magnetic field models, the impacts of electric and magnetic fields of HV transmission lines coupling with detonator firing circuits were investigated. Possible unintentional misfires under different scenarios and safe distance levels for operation of detonators in the proximity of transmission lines are proposed.

Keywords: Electrical Detonator, Modelling, Susceptibility, Misfire

\section{Introduction}

Transmission line configurations with high voltage and current levels generate large values of low frequency electromagnetic field stresses which in turn have significant interference on electrical and electronic equipment, accessories, circuits and other conducting bodies predominantly operating in frequency range below UHF [1].

The electromagnetic field levels in the close proximity of a high voltage transmission line depends on a number of variables, including but not limited to the voltage, current, overall geometry of the structures holding the conductors, the type of conductor, phase spacing, sag and earth wires used [2]. Hence, in the modelling and calculation process, each voltage level of the transmission lines has been considered separately and calculated independently for the specific structure, geometry and conductor type used [3], [4].

With the rapid development impetus in progress in the country, the need for enhancing the infrastructure to cater to that requirement is indispensable and a prerequisite. The development of road network, electricity, water and sanitation, housing and transportation are essentials in this respect.

The construction of these facilities, sometimes, involves blasting of ground rocks in order to level and pave the right of way.

Further, processed rock and rock metal are imperative raw materials that contribute towards the construction industry. This essential raw material is produced through the explosive blasting industry which is a prime industry in our modern society. It plays a part, direct or indirect, practically in everything we build, make, use and enjoy. Without the

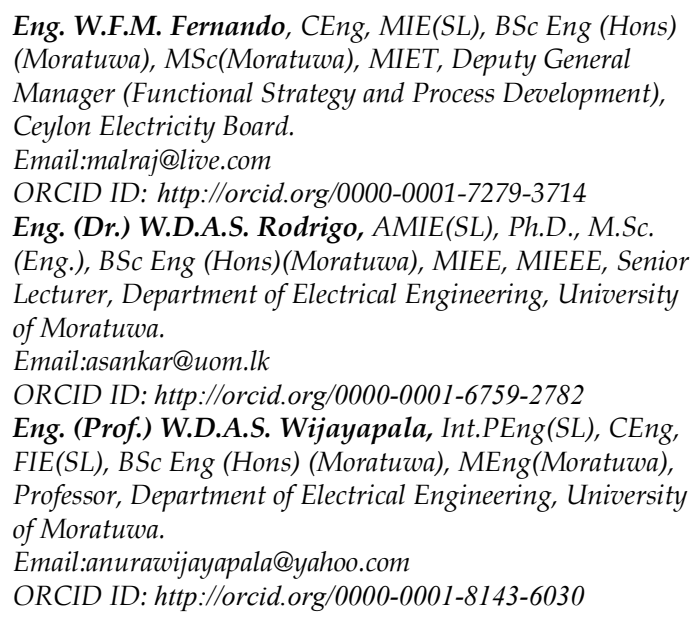


availability of explosives and blasting industry where and when they are needed, public works and private enterprises would be badly hampered. Therefore, facilitating, proper handling, transportation, storage and use of explosive materials in blasting industry while providing safeguards for life and property are in the interest of the whole community.

The interference and coupling of electromagnetic fields emanating from a transmission line becomes an issue when the explosive blasting activities are performed in its vicinity. Since the electrical detonator (one kind of electro explosive devices) and associated circuits are used as the means of initiating explosions, these electromagnetic fields could cause inductive coupling with the circuitry [3], [4]. The main research issue of concern is that whether there is a possibility that these couplings would induce significant voltages and threshold level currents that could initiate premature or unintentional explosions, and if so, what the safe distances are for operation of transmission lines.

This paper focuses on the fields emanating from high voltage transmission lines and their electromagnetic coupling effects on Electro Explosive Devices (EEDs) and their firing circuits. For that, following steps were followed:

- Study of detonators, circuit arrangements and explosives;

- Modeling and simulation of the electromagnetic fields;

- Verify the model with field measurements;

- Investigate the induced currents due to electric and magnetic fields; and

- Determine the safe distances.

\section{Electro Explosive Devices and Detonator Firing Circuits}

Electrical detonator is one type of Electro Explosive Device (EED) that is used to initiate blast sequences. Electrical detonators are compact devices that are designed to safely initiate and control the performance of larger explosive charges. They contain relatively high sensitive explosives which can be initiated by electrical or shock energy from an external source. All electrical detonators contain components that can be initiated by sufficient impact of electrical energy. These characteristics make them the most dangerous explosive products in industrial applications and they must be stored, transported, handled and used according to set procedures and regulations.

In the match-type blasting cap, the bridge wire is usually surrounded by a proprietary pyrotechnic mix or coating which is in turn surrounded by a primary explosive which is in contact with the main charge [3]. The principle of operation is, when a high enough electric current is passed through its lead wires, the bridg ewire in the fuse head is heated to the ignition temperature providing the initial activation energy, which then ignites the ignition charge (similar to a match) which in turn initiates the explosive in the bottom of the detonator [4].

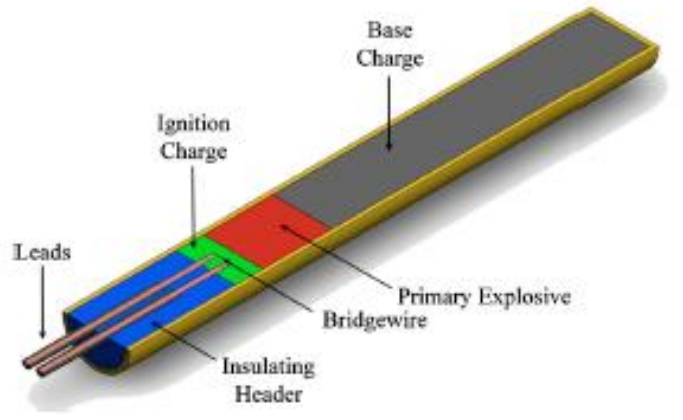

Figure 1 - Schematic Cross-Section of an Electrical Detonator [5]

The match-type EEDs have been found to be susceptible to such low levels of energy (4-6 $\mathrm{mJ}$ ) and the safe operation of these EEDs is vital when in use near sources that emits electromagnetic radiation [3] such as high voltage transmission lines, static electricity, radio frequency transmitters, lightning etc.

Under normal explosive operations, electrical energy is introduced into the detonator from the exploder (hand-driven magneto or charged capacitor) via a primary circuit wire (shotfiring cable) and detonator leads.

\subsection{Blasting Explosives}

Blasting explosives are agents that:

- Comprise ingredients by themselves are non-explosive; and

- Can only be detonated by a high explosive charge placed within it. The explosive charge comprises a detonator inserted inside gelignite (water-gel) capsules. Table 1 shows the essential components all blasting agents contain. 
Table 1 - Ingredients of Blasting Explosives

\begin{tabular}{|l|l|}
\hline Oxidizer & $\begin{array}{l}\text { A chemical that provides oxygen } \\
\text { for the reaction. Typical oxidizers } \\
\text { are ammonium nitrate and calcium } \\
\text { nitrate. }\end{array}$ \\
\hline Fuel & $\begin{array}{l}\text { A chemical that reacts with oxygen } \\
\text { to produce heat. Common fuel used } \\
\text { is diesel fuel oil. }\end{array}$ \\
\hline Sensitizer & $\begin{array}{l}\text { Provides the heat source ('hot spot') } \\
\text { to drive the chemical reaction of } \\
\text { oxidizer and fuel. Sensitizers are } \\
\text { entrapped air bubbles or pockets } \\
\text { within the explosive. }\end{array}$ \\
\hline
\end{tabular}

\subsection{Blasting Geometry}

The explosive blasting using electrical detonators have to be carefully planned so as to achieve the desired results. Number of bore holes, their diameter and depth, and spacing between the bore holes will be decided by the size of the burden and the final rock metal sizes to be achieved as a result of the blasting [6]. Therefore, the blasting geometry has to be carefully planned by experienced and skilled persons in the industry.

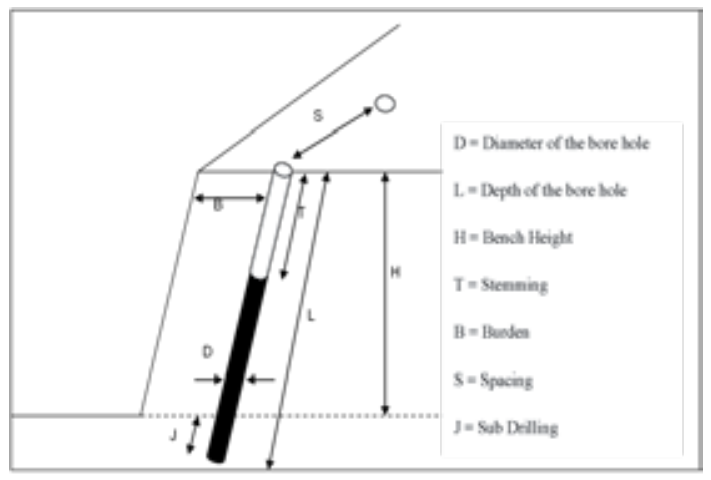

Figure 2 - Blasting Geometry

\subsection{Detonator Circuit Arrangements}

The simplest and most convenient way to connect electric detonators is in series. If one or more detonator connections are faulty then the entire circuit will not fire, eliminating the possibility of having explosive in the broken rock after firing. Connection in series allows the entire circuit to be tested for continuity and resistance from a safe place. In a parallel circuit, in which each detonator is connected across two common wires, each detonator or set of detonators is independent of the others. The circuit resistance is lower but even if one of the connections is faulty the remainder will fire, resulting in unexploded charges in the muck pile [6]. In general, detonator circuits are connected in a combination of series and parallel loops.

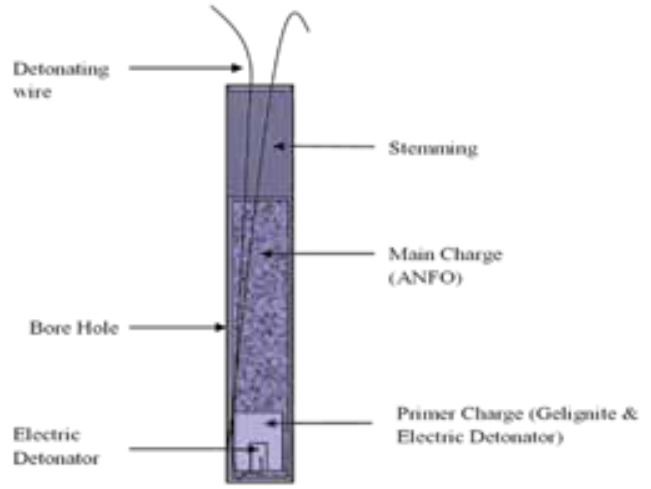

Figure 3 - Charged Bore Hole

\section{Modeling the Electromagnetic Field around Transmission Line}

\subsection{Electric Field Modeling}

From Coulomb's Law, for charges of $Q_{1}$ and $Q_{2}$, it is empirically derived that,

$F=\frac{Q_{1} \cdot Q_{2}}{4 \pi \epsilon_{0} R^{2}}$ in Newton

Electric field intensity, $E$, is the vector force on a unit positive charge, $E=\frac{F}{Q}$

$$
\begin{aligned}
& E=\frac{Q}{4 \pi \epsilon_{0} R^{2}} \hat{a}_{\mathrm{R}} \quad \text { or } \\
& E_{r}=\frac{Q}{4 \pi \epsilon_{0} r^{2}}
\end{aligned}
$$

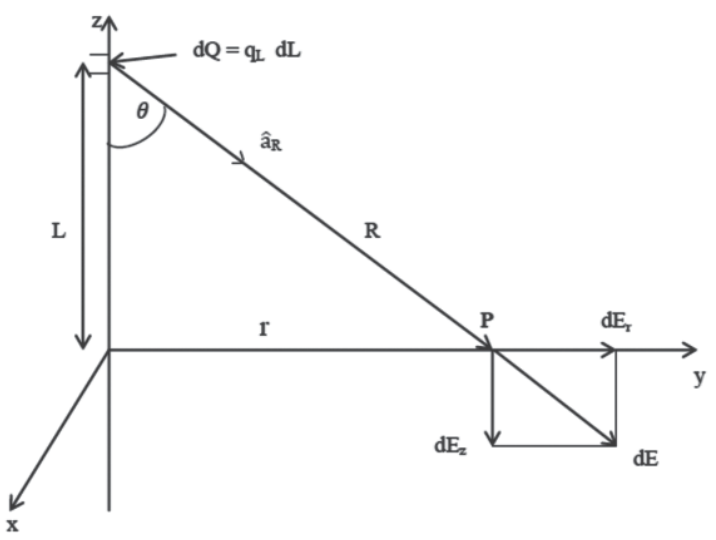

Figure 4 - Field of a Line Charge (for an Infinitely Long Conductor)

In a cylindrical coordinate system, as shown in Figure 4, the electrical field intensity, E, at any and every point resulting from a uniform line charge density $q_{L}$ could be determined as follows [2]. Incremental field at $P$ due to incremental charge, $d Q=q_{L} d L$

$$
\begin{aligned}
& d E=\frac{q_{L} d L}{4 \pi \varepsilon_{0} R^{2}} \text { or } \\
& d E_{r}=\frac{q_{L} d L \sin \theta}{4 \pi \varepsilon_{0} R^{2}}=\frac{q_{L} d L}{4 \pi \varepsilon_{0} R^{2}} \cdot \frac{y}{R} \\
& d E_{r}=\frac{q_{L} d L \cdot r}{4 \pi \varepsilon_{0} R^{3}}
\end{aligned}
$$


Replacing $R^{2}=L^{2}+r^{2}$ and summing up the contributions from every element of charge

$$
E_{r}=\frac{q_{L}}{2 \pi \varepsilon_{0} r}
$$

\subsubsection{Electric Field and Electric Potential}

By definition of potential difference, over a small length of $\delta l$ if the potential drops is $\delta v$,

$E=-\frac{\partial v}{\partial l}$

$=-\operatorname{grad} V=-\nabla V$

$\mathrm{Z}$ components cancel off. Hence,

$$
\vec{E}(x, y)=-\nabla \cdot V(x, y)
$$

For evaluation of the potential (work done in bringing a unit charge from infinity)

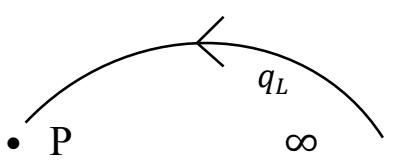

$V=\int_{\infty}^{r} E \cdot \mathrm{d} r=\left(\frac{q_{L}}{2 \pi \in \mathrm{o}}\right) \ln (r)$

\subsubsection{Addition of Potential Line Charges}

For a group of line conductors, by using the principle of superposition [7],

$V_{p}=\left[\frac{1}{2 \pi \in o}\right]\left(\left(q_{1} \cdot \ln \left(r_{1}\right)+q_{2} \ln \left(r_{2}\right)+\ldots+q_{n} \ln \left(r_{n}\right)\right)\right.$

Considering the special case of two-line charges and they are equal and opposite,

$$
V_{p}=\left[\frac{q}{2 \pi \in o}\right]\left\{\ln \left(r_{1}\right)-\ln \left(r_{2}\right)\right\}
$$

\subsubsection{Modeling the Line Charges}

$$
\begin{aligned}
d_{e q}= & D \sqrt[n]{\frac{n \cdot d}{D}} \quad D=\frac{s}{\sin ^{\pi} / n} \\
& D-\text { Bundle Diameter } \\
& d-\text { sub conductor diameter } \\
& N, n-\text { no. of sub conductor } \\
& S-\text { sub conductor spacing }
\end{aligned}
$$

Starting from Gauss' Law and from Equation (6), it can be derived that the potential of conductor 1 due to its own charge and its image charge with respective to ground,

$$
\begin{aligned}
& V_{1,1}=\left(\frac{q_{1}}{2 \pi \in o}\right) \ln \left(\frac{2 y_{1}}{d / 2}\right) \\
& V_{1,1}=\left(\frac{q_{1}}{2 \pi \in o}\right) \cdot P_{11} \\
& V_{1,2}=\left(\frac{q_{2}}{2 \pi \in o}\right) \cdot P_{12}
\end{aligned}
$$

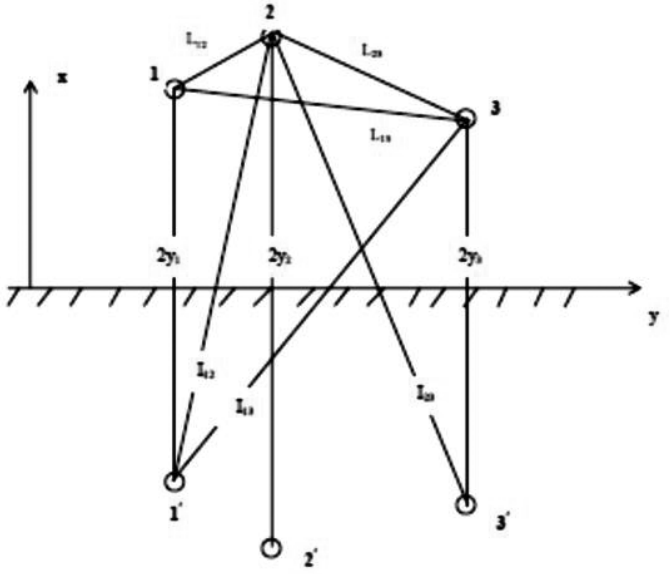

Figure 5 - Multi-Conductor Line for Calculation of Maxwell's Potential Coefficients

In general

$$
\begin{aligned}
& P_{i i}=\frac{1}{2 \pi \epsilon} \ln \left(\frac{4 y_{i}}{d_{i}}\right) \text { for } i=j \\
& P_{i j}=\frac{1}{2 \pi \epsilon} \ln \left[\frac{\left(\mathrm{x}_{\mathrm{i}}-\mathrm{x}_{\mathrm{j}}\right)^{2}+\left(\mathrm{y}_{\mathrm{i}}+\mathrm{Y}_{\mathrm{j}}\right)^{2}}{\left(\mathrm{x}_{\mathrm{i}}-\mathrm{x}_{\mathrm{j}}\right)^{2}+\left(\mathrm{Y}_{\mathrm{i}}-\mathrm{Y}_{\mathrm{j}}\right)^{2}}\right]^{\frac{1}{2}} \text { for } i \neq j
\end{aligned}
$$

In Matrix form $\quad[V]_{n}=[P]_{n n}[Q]_{n}$

$\left[V_{n}\right]=\left[V_{1}, V_{2}, \ldots . . V_{n}\right]_{n}$ - Potentials with respect to ground

$[Q]_{n}=\left[Q_{1}, Q_{2}, \ldots . Q_{n}\right]_{t}$ - Conductor charges $[P]_{n n}$ - Maxwell's Potential Matrix

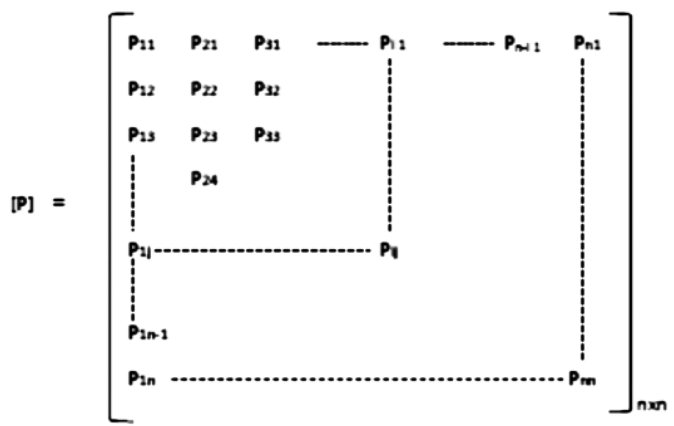

Once the Potential Matrix is known, the inverse of the matrix, $[P]^{-1}$ could be determined [6].

Since, $[P]^{-1}$ is known,

$$
[Q]=[P]^{-1}[V] \text { could be determined. }
$$

Considering the real and imaginary components,

$$
\begin{gathered}
{[Q]_{n}=\left(q_{i}\right)_{n \times 1}=\left(q_{i(r e)}+j q_{i(i m)}\right)_{n \times 1}} \\
=\left[Q_{r e}\right]+j\left[Q_{i m}\right]
\end{gathered}
$$


3.1.4 Electric Field at a Point in Space

For a line charge of Conductor $I$ with its mirror image,

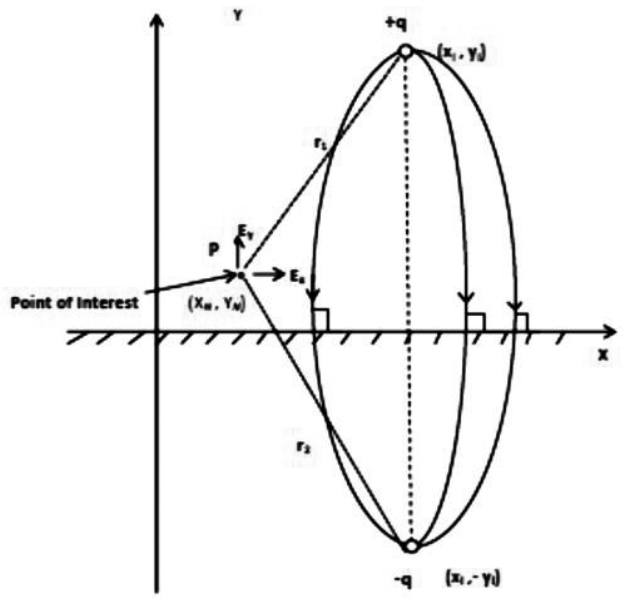

Figure 6 - Electric Field at a Point in Space due to Charge $q$ and its Mirror Image $-q$

$$
\begin{aligned}
& V_{P}=\left\{\frac{q}{2 \pi \epsilon} \ln \frac{r_{1}}{Y_{i}}-\frac{q}{2 \pi \epsilon} \ln \frac{r_{2}}{Y_{i}}\right\}=V_{N, i} \\
& r_{1}=\sqrt{\left(x_{i}-x_{N}\right)^{2}+\left(Y_{i}-Y_{N}\right)^{2}}, \\
& r_{2}=\sqrt{\left(x_{i}-x_{N}\right)^{2}+\left(Y_{i}+Y_{N}\right)^{2}} \\
& V_{N, i}=\frac{q}{2 \pi \epsilon o}\left\{\ln \left(\frac{\sqrt{\left(X_{i}-X_{N}\right)^{2}+\left(Y_{i}-Y_{N}\right)^{2}}}{Y_{i}}\right)-\right. \\
& \left.\operatorname{In}\left(\frac{\sqrt{\left(X_{i}-X_{N}\right)^{2}+\left(Y_{i}+Y_{N}\right)^{2}}}{Y_{i}}\right)\right\}
\end{aligned}
$$

For the total charge in the $i^{\text {th }}$ conductor $q_{i}$

$$
q_{i}=q_{r, i}+j q_{i m, i}
$$

The space potential is due to all conductors 1 , $2,3 \ldots \ldots n$

$$
\begin{aligned}
V_{N} & =V_{N, 1}+V_{N, 2}+V_{N, 3}+\ldots+V_{N, n} \\
& =\sum_{i=1}^{n} V_{N . i}
\end{aligned}
$$

From Equation 6, we have

$\vec{E}(x, y)=-\nabla V(x, y)$

Therefore,

$$
\begin{aligned}
& E_{x, i}=\frac{\left(q_{r, i}+j q_{i m, i}\right)}{2 \pi \in o}\left\{\frac{\left(X_{N}-X_{i}\right)}{\left(X_{i}-X_{N}\right)^{2}+\left(Y_{i}-Y_{N}\right)^{2}}-\right. \\
& \left.\frac{\left(X_{N}-X_{i}\right)}{\left(X_{i}-X_{N}\right)^{2}+\left(Y_{i}+Y_{N}\right)^{2}}\right\} \\
& E_{y, I}=\frac{\left(q_{r i}+j q_{i m, i}\right)}{2 \pi \in o}\left\{\frac{\left(Y_{N}-Y_{i}\right)}{\left(X_{i}-X_{N}\right)^{2}+\left(Y_{i}-Y_{N}\right)^{2}}-\right. \\
& \left.\frac{\left(Y_{N}-Y_{i}\right)}{\left(X_{i}-X_{N}\right)^{2}+\left(Y_{i}+Y_{N}\right)^{2}}\right\}
\end{aligned}
$$

Horizontal components and vertical components of $E_{x}, E_{y}$ are calculated for all the conductors, 1, 2, 3 ....... N [6]

$$
\begin{aligned}
& \vec{E}_{x}=\vec{E}_{x, r e}+j \vec{E}_{x, i m} \vec{E}_{y}=\vec{E}_{y, r e}+j \vec{E}_{y, i m} \\
& \vec{E}_{r e}=E_{x, \text { re }} \cdot \hat{\mathrm{u}}_{x}+E_{y, \text { re }} \cdot \hat{\mathrm{u}}_{y}
\end{aligned}
$$

$\vec{E}_{i m}=E_{x, i m \cdot} \cdot \hat{\mathrm{u}}_{x}+E_{y, i m} \cdot \hat{\mathrm{u}}_{y}$

$\hat{\mathrm{u}}_{x}, \hat{\mathrm{u}}_{y}$-Unit vectors in the directions of $x \& y$

3.1.5 Magnitude of $E$

$$
\begin{aligned}
E & =\sqrt{\left|E_{r e}^{2}\right|+\left|E_{i m}^{2}\right|} \\
& =\sqrt{E_{x, r e}^{2}+E_{x, i m}^{2}+E_{y, r e}^{2}+E_{y, i m}^{2}}
\end{aligned}
$$

Phase $\measuredangle: \theta_{r}=\tan ^{-1}\left(\frac{E_{i m}}{E_{r e}}\right)$

\subsubsection{Calculation of Potential}

From Equation (11)

$$
\begin{aligned}
& V_{N, i}=\frac{\left(q_{r, i}+j q_{i m, i}\right)}{2 \pi \epsilon}\left\{\ln \left(\frac{\sqrt{\left(X_{i}-X_{N}\right)^{2}+\left(Y_{i}-Y_{N}\right)^{2}}}{Y_{i}}\right)\right\} \\
& -\frac{\left(q_{r, i}+j q_{i m, i}\right)}{2 \pi \epsilon}\left\{\ln \left(\frac{\sqrt{\left(X_{i}-X_{N}\right)^{2}+\left(Y_{i}+Y_{N}\right)^{2}}}{Y_{i}}\right)\right\} \\
& V_{N}=V_{N, r e,}+j V_{N, i m}
\end{aligned}
$$

Magnitude of the potential is given by

$V_{N}=\sqrt{\left(\sum_{i=1}^{n} V_{i, r e}\right)^{2}+\left(\sum_{i=1}^{n} V_{i, i m}\right)^{2}}$

\subsubsection{Simulations Using MATLAB}

Transmission line data such as minimum clearance from ground, height of conductors at the tower level, the length of the basic span, distance of conductors from the tower center, number of conductors, conductor spacing in the bundle and the conductor diameter were considered in developing the model. The values thus considered are average values of real parameters of the line configurations used in Sri Lanka.

Once all the data were available, MATLAB programming was used for simulation of the electric field profiles. For array based input data, MATLAB is a handy tool for rigorous and complicated calculations [8].

\subsubsection{Simulation Results of the Model}

Some of the profiles drawn are given below. The model developed can accommodate any number of conductors in any configuration and takes the effect of earth conductors also into consideration in calculations. 


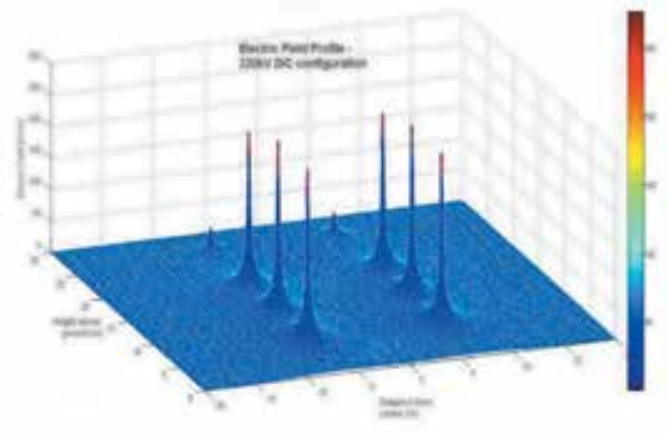

Figure 7 - Electric Field Variations with Height Above Ground

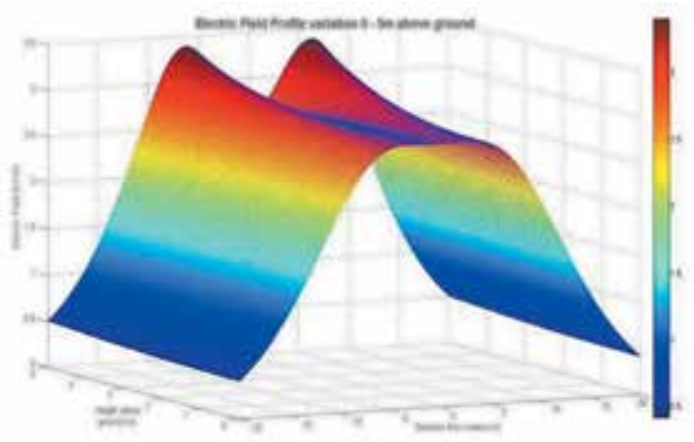

Figure 8 - 3D Scheme of Electric Field Variation for $132 \mathrm{kV}$ Double Circuit 0-5m Above Ground



Figure 9 - Electric Field Variation for $220 \mathrm{kV}$ Double Circuit Line 1m Above Ground

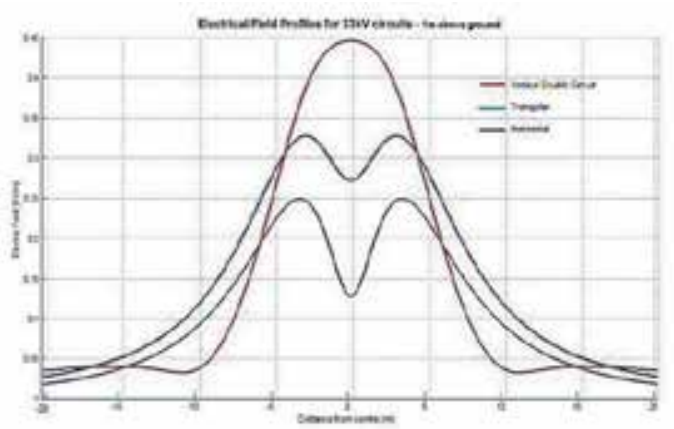

Figure 10 - Electric Field Variation for $33 \mathrm{kV}$ Double Circuit, Triangular and Horizontal Configurations, $1 \mathrm{~m}$ above Ground
Similarly, potential variation profile in space could be calculated with the use of above transmission line data.



Figure 11 - Space Potential Variation for 220 kV and 132 kV Double Circuit Lines 1m Above Ground

\subsection{Magnetic Field Modeling}

By the application of Biot-Savart's law, magnetic field $B$ at a point $P$ at a distant $r$ from an infinitely long straight line conductor carrying a current $I$ is given by [1]

$$
B=\frac{\mu_{0} I}{2 \pi r}
$$

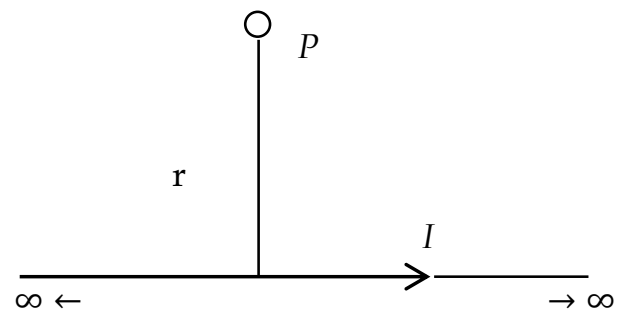

Figure 12 - An Infinitely Long Conductor Carrying Current $I$

The direction of $B$ is circumferential, i.e. normal to the plane of the paper, and coming out of it. Then,

\section{$B(2 \pi r)=\mu_{0} I$}

i.e. the vector $B$ multiplied by the length of the contour, is proportional to the current in the wire. From Ampere's law the vector $\mathrm{H}$ magnetic field intensity can be defined such that,

$$
H=\frac{B}{\mu}
$$

Hence in general,

$$
H=\frac{I}{2 \pi r}
$$




\subsubsection{Modeling for ' $n$ ' Number of Conductors}

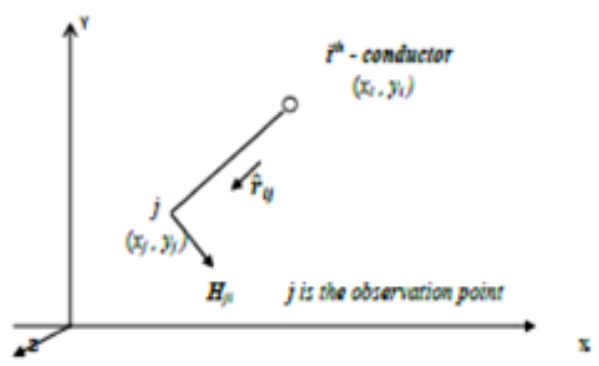

Figure 13 - Coordinate System for Magnetic Field Calculations

Considering only one conductor, in vectoral notation,

$$
\overrightarrow{\boldsymbol{H}}_{j i}=\frac{\vec{I}_{\mathrm{i}} x \hat{\boldsymbol{r}}_{j i}}{2 \pi r_{i j}}=\frac{I_{\mathrm{i}}}{2 \pi r_{i j}} \widehat{\emptyset}_{i j}
$$

$\varnothing_{i j}$ is the unit vector in the direction of the product of the vector current and the vector segment $r_{i j}$.The unit vector is equal to;

$$
\widehat{\emptyset}_{i j}=-\frac{Y_{i}-Y_{j}}{r_{i j}} \overrightarrow{\boldsymbol{u}}_{\boldsymbol{x}}+\frac{X_{i}-X_{j}}{r_{i j}} \overrightarrow{\boldsymbol{u}}_{\boldsymbol{y}}
$$

$\overrightarrow{\mathbf{u}}_{\mathbf{x}}, \overrightarrow{\mathbf{u}}_{\mathbf{y}}$ are the unit vectors in $x, y$ directions.

$$
\begin{aligned}
\overrightarrow{\mathbf{H}}_{\mathbf{j}} & =\sum_{\mathrm{i}=1}^{\mathrm{n}} \frac{\mathrm{I}_{\mathrm{i}}}{2 \pi \mathrm{r}_{\mathrm{ij}}} \widehat{\emptyset}_{\mathrm{ij}} \\
\boldsymbol{B}_{j} & =\mu_{\text {air }} \boldsymbol{H}_{\boldsymbol{j}}
\end{aligned}
$$

where $r_{i j}=\sqrt{\left(x_{i}-x_{j}\right)^{2}+\left(y_{i}-y_{j}\right)^{2}}$ is the direct distance from $i$ th conductor to the point of interest.

\subsubsection{Consideration of the Effects of Earth's Return Currents ;}

The magnetic field [6] produced by each conductor and its earth return is expressed by;

$$
\begin{aligned}
& \boldsymbol{H}_{i j_{\text {earth }}}=\sum_{i=1}^{n} \frac{I_{\mathrm{i}}}{2 \pi r_{i j}^{\prime}}\left(1+\frac{1}{3}\left(\frac{I_{\mathrm{i}}}{\gamma_{i j}}\right)^{4}\right) \widehat{\varnothing}_{\imath \jmath} \\
& \gamma=\sqrt{j \omega \mu(\sigma+j \omega \epsilon)}
\end{aligned}
$$

$\omega$-angular frequency $\mu$-permeability of earth $\sigma$-Earth's Conductivity $0.001-0.002 \mathrm{~s} / \mathrm{m} \quad \epsilon-$ earth's permitivity

$$
\begin{gathered}
\mathrm{r}_{\mathrm{ij}}^{\prime}=\sqrt{\left(\mathrm{x}_{\mathrm{i}}-\mathrm{x}_{\mathrm{j}}\right)^{2}+\left(\mathrm{y}_{\mathrm{i}}-\mathrm{y}_{\mathrm{j}}+\frac{2}{\gamma}\right)^{2}} \\
\widehat{\phi}_{\imath \mathrm{j}}=-\left[\frac{y_{i}-y_{j}+\frac{2}{\gamma}}{r_{i j}}\right] \widehat{\boldsymbol{u}}_{x}+\left(\frac{x_{i}-x_{j}}{r_{i j}}\right) \widehat{\boldsymbol{u}}_{y}
\end{gathered}
$$

\subsubsection{Resultant Effect of Magnetic Field} Intensity

$\boldsymbol{H}_{j}=\sum_{i=1}^{n} \frac{I_{\mathrm{i}}}{2 \pi r_{i j}} \widehat{\phi}_{i j}-\sum_{i=1}^{n} \frac{I_{\mathrm{i}}}{2 \pi r_{i j}^{\prime}}\left(1+3\left(\frac{2}{\gamma r_{i j}^{\prime}}\right)^{4}\right) \widehat{\phi}_{i j}$

$$
\mathbf{H}_{\mathbf{j}}=\mathrm{H}_{\mathrm{xj}} \widehat{\mathbf{u}}_{\mathrm{x}}+\mathrm{H}_{\mathrm{yj}} \widehat{\mathbf{u}}_{\mathrm{y}}
$$

Where, $H_{x j}=H_{x, r}+j H_{x, i m}$

$$
\begin{gathered}
H_{y j}=H_{y, r}+j H_{y, i m} \\
\vec{H}_{r}=H_{x, r} \hat{u}_{x}+H_{y, r} \hat{u}_{y} \\
\vec{H}_{i}=H_{x, i m} \hat{u}_{x}+H_{y, i m} \hat{u}_{y}
\end{gathered}
$$

Absolute value;

$$
\mathrm{H}_{\mathrm{T}}=\sqrt{\mathrm{H}_{\mathrm{x}, \mathrm{r}}^{2}+\mathrm{H}_{\mathrm{x}, \mathrm{im}}^{2}+\mathrm{H}_{\mathrm{y}, \mathrm{r}}^{2}+\mathrm{H}_{\mathrm{y}, \mathrm{im}}^{2}}
$$

\subsubsection{Simulation of Magnetic Field Profiles using MATLAB}

Using the same transmission line configuration data used for electric field modeling, magnetic field profiles were simulated using MATLAB. The model developed can accommodate any number of conductors in any configuration and takes the effect of earth conductors as well as the earth return currents into account. Some of the profiles obtained from the model are given below.

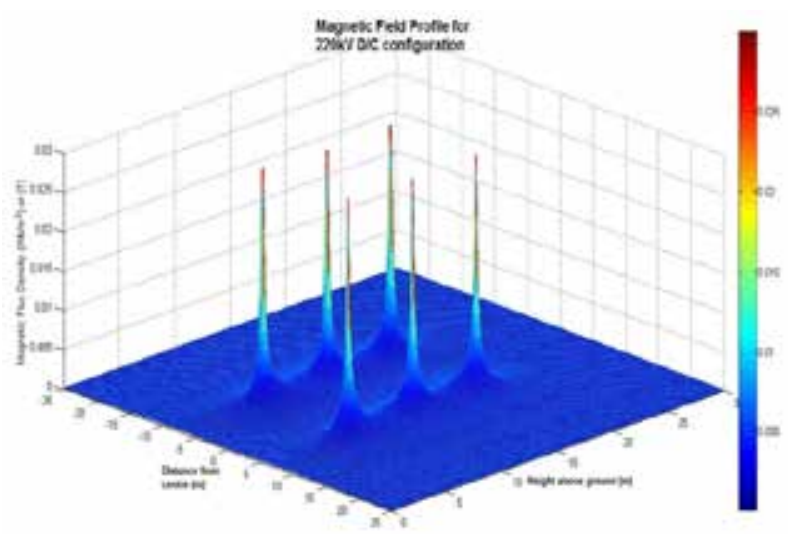

Figure 14 - Magnetic Field Variations with Respective to Height and Distance 


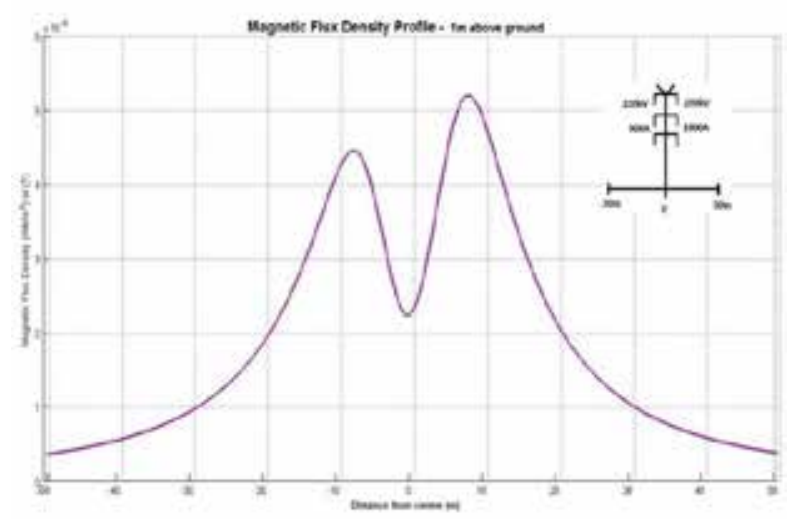

Figure 15 - Magnetic Field Variation for 220 kV Double Circuit Line 1m above Ground

\section{Validation of the Model by Measuring the Fields under the Transmission Lines}

\subsection{Measuring the Electric Field Under the Transmission Lines}

Once the model for the electric field around transmission line was developed, it was required to measure the electric field values physically in the field in order to verify the accuracy of the model. The sites for measuring electric field were selected so as to avoid any shielding effects from other structures and bushes at ground potential. Therefore, level terrains like paddy fields and flat grounds were selected avoiding irregular bushy terrains as much as possible.

Locations with nearby transmission lines which could interfere with the measuring fields were also avoided. Clear terrains of at least $200 \mathrm{~m}$ width were selected for taking measurements. Figure 17 shows such a location selected for taking measurement for $220 \mathrm{kV}$ transmission line.

\subsubsection{Instruments Used for Measuring}

For measuring the electric fields, AC Electric Field Meter Model ACEF manufactured by Alhpa Lab Inc., USA was used. This meter measures AC electric field in the vertical direction (same direction as the long axis of the meter). Absolute accuracy of the instrument is $40 \mathrm{~Hz}-1 \mathrm{kHz}$ is $+/-2 \%$ of the reading $+/-1$ count ( 1 count is 1 volt per meter). When taking measurements, the meter was kept at a fair distance as possible from the body in order for measuring the unperturbed electric field as closely as possible.

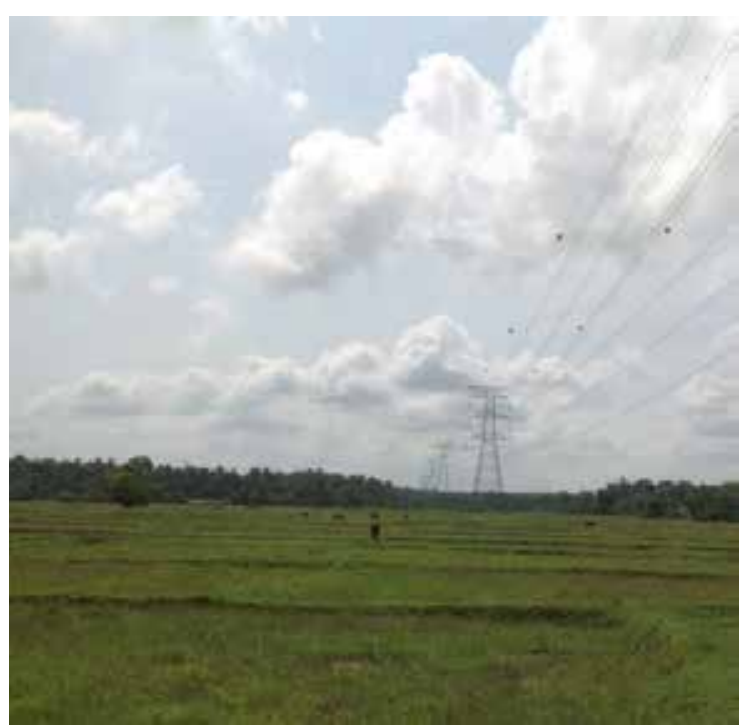

Figure 16 - Location Selected for Taking Measurements under a $220 \mathrm{kV}$ Line

For measuring the conductor heights, FLUKE 421D Laser Distance Meter was used. The accuracy of the meter is $\pm 1.5 \mathrm{~mm}$.

\subsubsection{Recording the Measurements}

The electric field measurements taken were recorded along with the values of voltages and currents in the circuits, line configurations, line conductor height etc. Table 2 gives a sample of the recorded measurements for Kotugoda Veyangoda $220 \mathrm{kV}$ double circuit twin zebra transmission line.

Table 2 - A Sample Electric Field Measurement Taken for KotugodaVeyangoda 220 kv Line

\begin{tabular}{|c|c|c|c|}
\hline $\begin{array}{l}\text { Distance } \\
\text { from } \\
\begin{array}{l}\text { centre } \\
(\mathrm{m})\end{array}\end{array}$ & $\begin{array}{l}\text { Electric } \\
\text { field } \\
(\mathrm{V} / \mathrm{m})\end{array}$ & $\begin{array}{l}\text { Distance } \\
\text { from } \\
\text { centre } \\
(\mathrm{m})\end{array}$ & $\begin{array}{l}\text { Electric } \\
\text { field } \\
(\mathrm{V} / \mathrm{m})\end{array}$ \\
\hline 0 & 3502 & 13.0 & 1700 \\
\hline 0.5 & 3472 & 13.5 & 1357 \\
\hline 1.0 & 3650 & 14.0 & 1290 \\
\hline 1.5 & 3750 & 14.5 & 1240 \\
\hline 2.0 & 3850 & 15.0 & 1100 \\
\hline 2.5 & 3980 & 15.5 & 1025 \\
\hline 3.0 & 4300 & 16.0 & 893 \\
\hline 3.5 & 4450 & 16.5 & 685 \\
\hline 4.0 & 4650 & 17.0 & 550 \\
\hline
\end{tabular}

The line currents for $220 \mathrm{kV}$ line were $670 \mathrm{~A}$ and $780 \mathrm{~A}$ and the line conductor height (lowest phase) was $8.6 \mathrm{~m}$. 
4.1.3 Comparison of the Profiles of Measured Electric Field Values with the Profile Generated by the Modeled

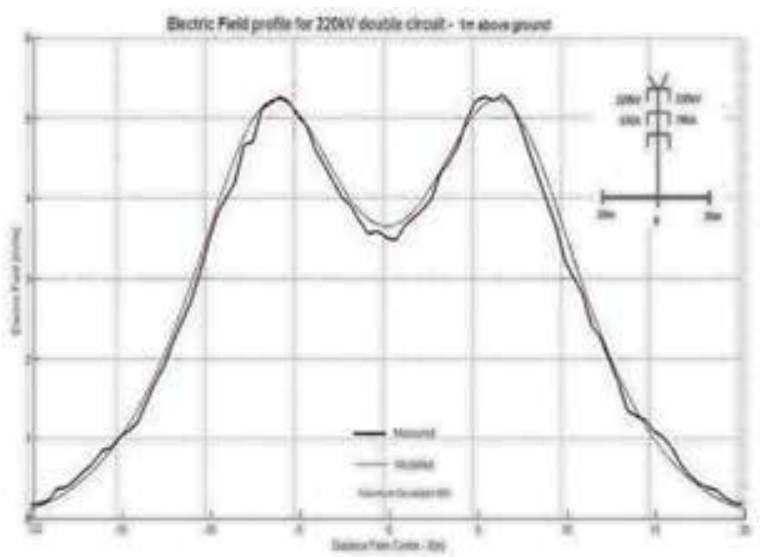

Figure 17 - Electric Field Profiles Comparing the Modeled and Measured Values for $220 \mathrm{kV}$ Double Circuit Configuration

The line currents for $33 \mathrm{kV}$ line were $165 \mathrm{~A}$ and 180 A while the line conductor height (lowest phase) was $5.4 \mathrm{~m}$.

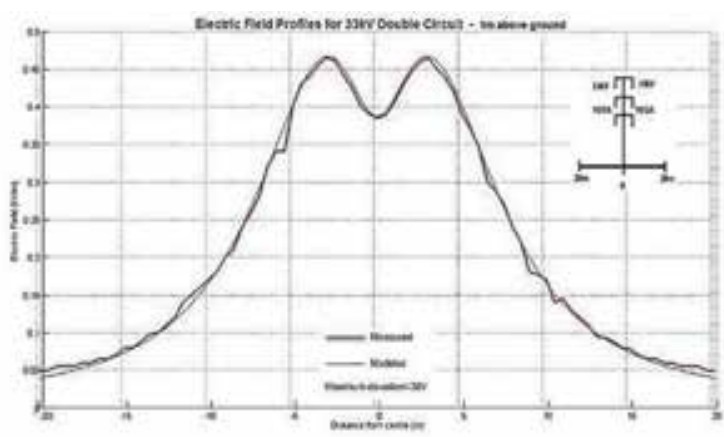

Figure 18 - Electric Field Profiles Comparing the Modeled and Measured Values for $33 \mathrm{kV}$ Double Circuit Configuration

\subsubsection{Comparison of the Measured Values and the Modeled Values and Validation of the Model \\ The deviations between measured and} modeled values are primarily due to interference of the person taking measurement with the electric field during the measuring process, changes in the medium of air such as moisture, wind speed etc. During the measuring process the $50 \mathrm{~Hz}$ electric field which is easily vulnerable to disturbances is disturbed while the modeled electric field represents the unperturbed electric field.

The profiles drawn verify that the measured values are very close to the modeled values and the profile shapes are the same. Since the electric field models developed for $220 \mathrm{kV}$ and $33 \mathrm{kV}$ match with the measured values, the accuracy of the model developed is amply verified.

\subsection{Measuring the Magnetic Field Under the} Transmission Lines

The sites for measuring magnetic field were also selected avoiding shielding effects from other structures and bushes at ground potential. Therefore, terrains like paddy fields and flat grounds were selected avoiding irregular bushy terrains as much as possible.

\subsubsection{Instruments and Recording of Measurements}

For measuring the magnetic fields, Tri-axial ELF Magnetic Field Meter of Model SK-8301 manufactured by Kaise Corporation, Japan was used. This meter measures AC magnetic field in the vertical direction (same direction as the long axis of the meter). The accuracy of the instrument at $50 / 60 \mathrm{~Hz}$ is $+/-2 \%$ and the resolution is . $01 \mu \mathrm{T}$.

\subsubsection{Plotting the Profiles of Measured Magnetic Field Values vs Modeled Values}



Figure 19 - Magnetic Field Profiles Comparing the Modeled and Measured Values for $220 \mathrm{kV}$ Double Circuit Configuration

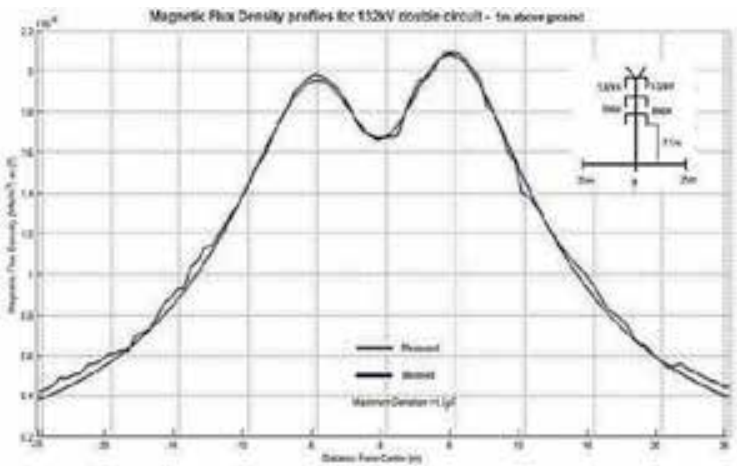

Figure 20 - Magnetic Field Profiles Comparing the Modeled and Measured Values for $132 \mathrm{kV}$ Double Circuit Configuration 


\subsubsection{Comparison of the Measured Values} and the Modeled Values of the Magnetic Fields and Verification of the Model

The field profiles comparing the measured values and the modeled values for magnetic field are drawn in Figures 19 and 20 for $220 \mathrm{kV}$ and $132 \mathrm{kV}$ double circuit twin zebra conductors, respectively. The deviations between measured and modeled values are primarily due to changes in the currents during measuring process, and changes in the medium of air such as moisture, wind speed etc. The current readings are the average value of the initial and final values measured at the grid substations.

The profiles drawn verify that the measured values are very close to the modeled values and the profile shapes are the same. Since the magnetic field models developed for 220 $\mathrm{kVand} 132 \mathrm{kV}$ matches with the measured values, the accuracy of the models developed is amply verified.

\section{Susceptibility of Detonators to the Electric and Magnetic Fields}

\subsection{Electric Field Couplings}

It was observed that the $50 \mathrm{~Hz}$ electric fields under the transmission line are significantly large and would be around $5 \mathrm{kV} / \mathrm{m}$ directly under the conductors of $220 \mathrm{kV}$ double circuit twin zebra line. Hence, it was of interest to investigate the behavior of detonators under the influence of electric fields of this scale.

\subsubsection{Testing of Detonators Placed Inside Electric Fields}

In the initial testing, a parallel metal sheet arrangement with $0.5 \mathrm{~m} \times 0.5 \mathrm{~m}$ plates was used to provide a uniform field for the detonators. Since the size of the explosion was unpredictable, it was not tested in the laboratory but tested in a blasting site at Panagoda under the supervision of license holders in blasting industry.

The detonator was placed between the parallel metal plates with its leads projecting towards the plates but not touching the plates. With this arrangement, electric fields of $2200 \mathrm{~V} / \mathrm{m}$ and $1450 \mathrm{~V} / \mathrm{m}$ were applied across the detonator using a hand driven portable exploder or shot blaster and the capacitor charge build-up type exploder respectively. But no explosion was observed.

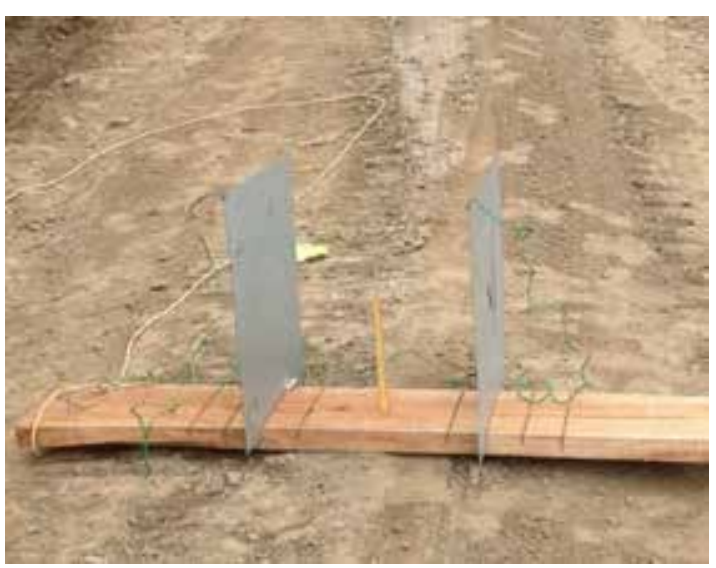

Figure 21 - Investigating the Behavior of Detonator Placed in an Electric Field Across Parallel Plate Arrangement

Since the size of the explosion of an electrical detonator is significantly large, it was decided to measure the induced currents in a conductor placed inside the electric field instead of placing the detonator itself directly. By this way, it is possible to determine the induced currents in the bridge wire of the detonator placed inside electric fields. But no induced currents in the conductor placed in an electric field over $12000 \mathrm{~V} / \mathrm{m}$ could be observed even in the range of micro-amperes. Hence, it was concluded that no significant current is induced in a bridge wire of an electro explosive device (EED) placed in a $50 \mathrm{~Hz}$ electric field emanating under a transmission line so as to initiate an inadvertent firing.

The effect of transient electric fields, in free space, also shows that the minimum energy threshold for ignition of commercial EEDs is not met for pulsed electric fields of $100 \mathrm{kV} / \mathrm{cm}$ [3].

\subsection{Magnetic Field Couplings}

\subsubsection{Relationship Between Induced emf $(E)$ and Magnetic Flux (B)}

Lenz's law states that "The direction of the induced electromagnetic force (emf) is such that any current which it produces, tends to oppose the change of flux" [1]. When the circuit is a simple, single-turn one, then the 'fluxlinkage' is the amount of the flux $\Phi$ which is passing through the single-turn coil.

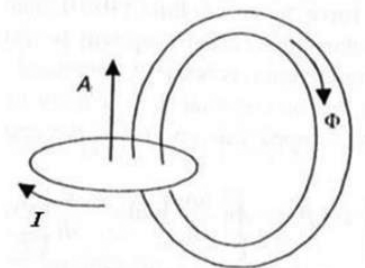

Figure 22 - Changing Flux-Linkage and Lenz's Law 
If the resultant flux through the circuit has the direction A and is increasing, induced current in the circuit will tend to set up a flux in the direction opposite to A. Hence, the direction of the current must be as shown by the arrow A.

Therefore, Faraday's law of induction can be formally stated giving the emf induced in a wire,

$$
E=-\frac{d \Phi}{d t}
$$

Hence, the generalization of Equation (12), for any loop whether of wire or otherwise is

$$
\oint E_{1} d l=-\frac{d \Phi}{d t}
$$

When flux $\Phi$ passes through an element with an area $\delta \mathrm{A}$,

$$
\Phi=B . \delta A
$$

Equation (13) becomes

$$
\begin{array}{r}
\oint E_{1} d l=-\delta A \cdot \frac{\partial B}{\partial t} \\
E=-\delta A \cdot \frac{\partial B}{\partial t}
\end{array}
$$

\subsubsection{Time Taken for Detonator to Fire}

Normal current required for firing $=1 \mathrm{~A}$

The Joule heating required, for the detonator to fire $\geq 5 \mathrm{~mJ}$ (As per detonator specification)

$\therefore$ Energy $=I^{2} . r . t=5 \mathrm{~mJ} \quad r=2 \mathrm{ohm}$

Time taken; $\quad t=2.5 \mathrm{~ms}$

Minimum Current Requirement for

Time taken; $\quad t=1 \mathrm{~s}$

$$
\text { detonator to fire }=50 \mathrm{~mA}
$$

The time taken for detonator to fire would be between $2.5 \mathrm{~ms}$ to $1 \mathrm{~s}$ depending on the current provided to the detonator.

\subsubsection{Minimum Flux Density Requirement for Firing

$$
B(t)=\sqrt{ } 2 . B_{r m s} \operatorname{Sin} \omega t
$$

Considering a loop area of $1 \mathrm{~m}^{2}$ with one detonator,

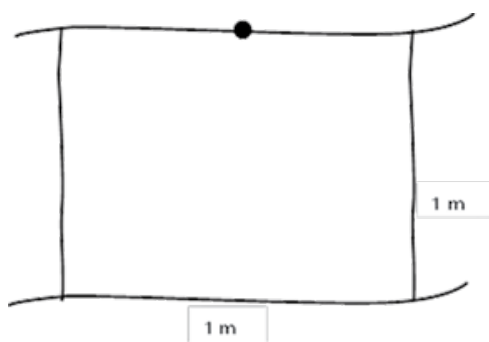

Figure 23 - $1 \mathrm{~m}^{2}$ Detonator Circuit Loop

Resistance of the lead wire $=0.1 \Omega / \mathrm{m}$ and detonator resistance $=2 \Omega$.

From Equations 13 and 14,

$$
\begin{aligned}
E= & \frac{-d \emptyset}{d t}=-\delta A \frac{d B}{d t} \\
& =-A \cdot \omega \cdot B_{r m s}=-1 .(2 \pi f) B_{r m s}
\end{aligned}
$$

For a loop resistance of $3 \Omega$,

$$
\begin{aligned}
& I=\frac{V}{R}=\frac{\omega \cdot B_{r m s}}{3} \geq 50 \mathrm{~mA} \\
& B_{r m s} \geq 47.75 \times 10^{-5} \mathrm{~T}
\end{aligned}
$$

When the flux density, $B$, exceeds $47.75 \times 10^{-5} \mathrm{~T}$, there is a possibility of detonator firing.

Energy supplied $=I^{2} r t$

$=\left(\frac{\omega .47 .75 \times 10^{-5}}{3}\right)^{2} \times 2 \times 1>5 \mathrm{~mJ}$

This implies that when a flux density exceeds $47.75 \times 10^{-5} \mathrm{~T}$, the detonator would initiate firing and the distance at which this occurs could be determined from the magnetic flux density variation profile simulated for $0.5 \mathrm{~m}$ above the ground.

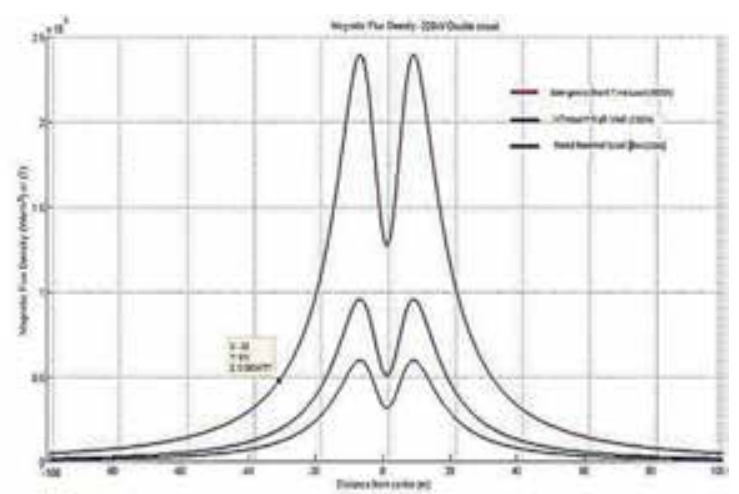

Figure 24 - Flux Density Variations for Different Loadings for $220 \mathrm{kV}$ Double Circuit Twin Conductor Configuration

It is observed from the magnetic field profiles for rated loading, infrequent high loading and emergency short time loading, the safe distance for $220 \mathrm{kV}$ transmission line is $32 \mathrm{~m}$ away from the center of the line.

Similarly, for $132 \mathrm{kV}$ twin zebra and $33 \mathrm{kV}$ raccoon conductor double circuit configurations, the flux density profiles $0.5 \mathrm{~m}$ above ground can be plotted and it was found that the safe distances for $132 \mathrm{kV}$ and $33 \mathrm{kV}$ 
transmission lines are $26.6 \mathrm{~m}$ and $6.7 \mathrm{~m}$ from the center of the line.

5.2.3 Inducements of Current in the Detonator Circuits Caused by Current Surges Occurring in Transmission Lines.



Figure 25 - A Typical Current Surge that Occurs in a Transmission Line

From Equation (13), induced emf

$E=-\delta A \cdot \frac{d B}{d t} \quad=-A \cdot \frac{\Delta B}{\Delta t} \Delta B=B_{D}$

For $t_{1}$ of Surge

$$
E=\frac{-B_{D}}{t_{1}} \rightarrow \quad I_{1}=\frac{B_{D}}{R t_{1}}
$$

For $t_{2}$ of Surge

$$
E=\frac{B_{D}}{t_{2}} \rightarrow I_{2}=\frac{B_{D}}{R t_{2}}
$$

For both inducements to cause the detonator initiation;

$$
\begin{gathered}
5 \mathrm{~mJ} \leq I_{1}^{2} r t_{1}+I_{2}^{2} r t_{2} \\
\leq \frac{r B_{D}^{2}}{R^{2}}\left(\frac{1}{t_{1}}+\frac{1}{t_{2}}\right) \\
B_{D} \geq \sqrt{\frac{5 \times 10^{-3} \times R^{2}}{r\left(\frac{1}{t_{1}}+\frac{1}{t_{2}}\right)}}
\end{gathered}
$$$$
\leq \frac{B_{D}^{2}}{R^{2} t_{1}^{2}} \cdot r \cdot t_{1}+\frac{B_{D}^{2}}{R^{2} t_{2}^{2}} \cdot r \cdot t_{2}
$$

This gives the minimum requirement of flux linkage due to a surge current in order for detonation to take place [1].

\subsubsection{Inducements Caused by Transmission Line Faults}

Transmission line fault currents will depend on the type of fault, the fault level, line impedance etc. Three phase line-to-line fault will cause the most severe currents due to the low impedance compared to other types of faults. Depending on the fault level, the fault currents in $220 \mathrm{kV}$ system could be as high as $40 \mathrm{kA}$ but on the average, a fault current of $25 \mathrm{kA}$ is considered for $220 \mathrm{kV}$ system and fault currents of $15 \mathrm{kA}$ and $10 \mathrm{kA}$ are considered for $132 \mathrm{kV}$ and $33 \mathrm{kV}$ systems, respectively.

It is evident from most of the transmission line faults that the fault rise time is around half a cycle while the average fault persistent time is about five cycles (Cycle time is $20 \mathrm{~ms}$ for a $50 \mathrm{~Hz}$ system). Taking these facts into account, a minimum flux linkage requirement for detonator initiation can be calculated and the minimum safe distance can be determined.

$\delta A=1 \mathrm{~m}^{2}, t_{1}=10 \mathrm{~ms}, t_{2}=80 \mathrm{~ms}, \omega=2 \pi f$,

$r=2 \Omega, R=3 \Omega$

For the fault rise time $E=-1 \cdot \frac{\Delta B}{t_{1}}$

For the fault persistent time

$$
E=-\delta A . \omega . \Delta B
$$

Energy $_{1}=\left(\frac{\Delta B}{R t_{1}}\right)^{2} \times 2 \times t_{1}$

Energy $_{2}=\left(\frac{100 \pi . \Delta B}{R}\right)^{2} \times 2 \times t_{2}$

Energy $_{1}+$ Energy $_{2} \geq 5 m J$

Therefore $\mathrm{B} \geq 167.75 \times 10^{-5} \mathrm{~T}$

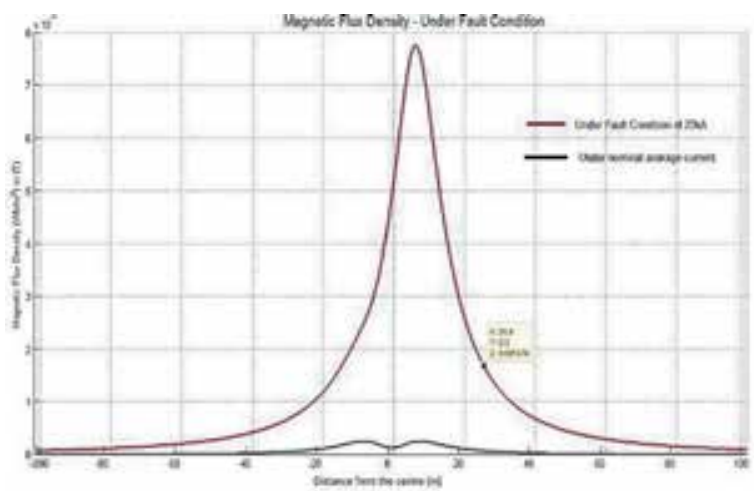

Figure 26 - Flux Density Variations due to a Line Fault Current of $20 \mathrm{kA}$ for $220 \mathrm{kV}$ Double Circuit Twin Conductor Configuration

It is observed from magnetic field profile shown in Figure 30, for a fault current of $20 \mathrm{kA}$, the safe distance for $220 \mathrm{kV}$ transmission line is $31.4 \mathrm{~m}$ from the center of the line.

In a similar manner, fault currents of $15 \mathrm{kA}$ and $10 \mathrm{kA}$ are considered for $132 \mathrm{kV}$ and $33 \mathrm{kV}$ circuits respectively to find safe distances under fault conditions. It can be shown that the safe distances under these fault conditions for $132 \mathrm{kV}$ and $33 \mathrm{kV}$ double circuit configurations are $10.2 \mathrm{~m}$ and $9.1 \mathrm{~m}$, respectively. 


\subsubsection{Inducements Caused by Travelling} Lightning Waves in Transmission Lines

Lightning is always a major threat encountered in the blasting industry. All explosive activities should be suspended at the sign of thunder storms approaching or if there is any possibility of occurrence of lightning [6]. There may not be any sign of lightning or rain in the vicinity, but there is a possibility that lightning travels several miles as travelling waves along the power transmission lines and inducing currents in detonator circuits in close proximity sufficient enough to cause unanticipated firing [9]. The travelling waves could cause currents of only several kA at the discharge but $20 \mathrm{kA}$ discharge current as a result of a direct stroke in the $220 \mathrm{kV}$ transmission line is considered as the worst case.

A travelling wave with a lesser steepness is considered assuming it has travelled more than $25 \mathrm{~km}$.

From Equation (15) and for $t_{1}=100 \mu \mathrm{s}$ and $t_{2}=$ $800 \mu \mathrm{s}$,

$R=3 \Omega, r=2 \Omega$

The requirement in flux density for inducing 5 $\mathrm{mJ}$ in detonator circuit is given by,

$B_{D} \geq \sqrt{\frac{5 \times 10^{-3} \times R^{2}}{r\left(\frac{1}{t_{1}}+\frac{1}{t_{2}}\right)}} \quad=141.4 \times 10^{-5} \mathrm{~T}$

This implies that when the flux density exceeds the value $141.4 \times 10^{-5} \mathrm{~T}$, the detonator would initiate firing and the distance at which this occurs could be determined from the magnetic flux density variation profile simulated for 0.5 $\mathrm{m}$ above the ground (Figure 31) for the lightning surge.

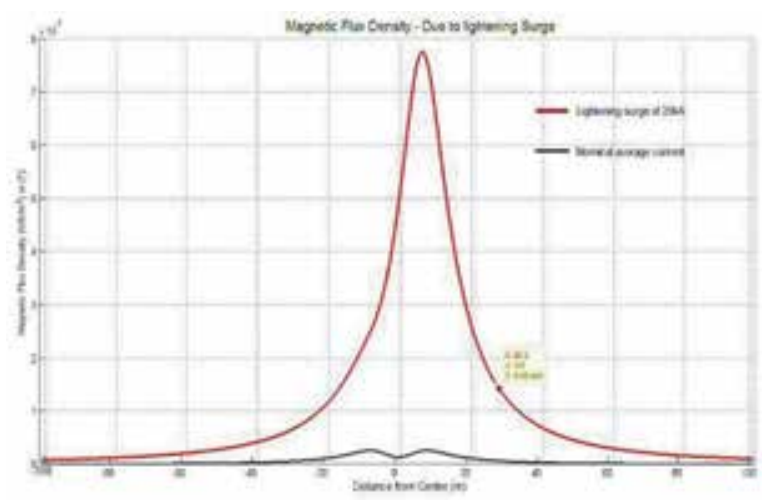

Figure 27 - Flux Density Variations due to 20 kA Lightning Surge for $220 \mathrm{kV}$ Double Circuit Twin Conductor Configuration

It is observed from the magnetic field profile for a lightning surge of $20 \mathrm{kA}$, the safe distance for $220 \mathrm{kV}$ transmission line is $29.5 \mathrm{~m}$ from the center of the line.

Similarly, lightning discharge currents of $15 \mathrm{kA}$ and $10 \mathrm{kA}$ with the same impulse shape with $\mathrm{t}_{1}$ $=200 \mu \mathrm{s}$ and $t_{2}=1000 \mu \mathrm{s}$ are considered for 132 $\mathrm{kV}$ and $33 \mathrm{kV}$ circuits to find safe distances under travelling lightning wave conditions. It can be shown that the safe distances under these conditions for $132 \mathrm{kV}$ and $33 \mathrm{kV}$ double circuit configurations are $16.6 \mathrm{~m}$ and $8.3 \mathrm{~m}$, respectively.

\subsection{Safe Distances}

The safe distance values corresponding to different scenarios of loading, faults and travelling waves, and providing a further tolerance of $20 \%$ as a safety margin, final safe distances are summarized in Table 3.

\section{Conclusions and Recommendations}

The simulated results of the models developed in this research for the electric and the magnetic fields are validated by the field measured data very closely following the simulated values of the model. Therefore, the models can be used reliably for the purposes of investigations and analysis of electromagnetic fields around transmission lines.

Table 3 - The Safe Distances Corresponding to Different Loading Conditions, Faults and Lightning

\begin{tabular}{|c|c|c|c|c|}
\hline \multirow{2}{*}{$\begin{array}{l}\text { Voltage } \\
\text { \&cctCon } \\
\text { fig. }\end{array}$} & \multicolumn{3}{|c|}{ Safe Distance (m) } & \multirow{2}{*}{$\begin{array}{c}\text { Rounded } \\
\text { off Safe } \\
\text { Distance } \\
\text { with a } \\
\text { Tolerance } \\
\text { of } 20 \% \\
\text { (m) }\end{array}$} \\
\hline & $\begin{array}{l}\text { Max. } \\
\text { due to } \\
\text { loading }\end{array}$ & $\begin{array}{c}3 \emptyset \\
\text { Fault } \\
s\end{array}$ & $\begin{array}{l}\text { Lightning } \\
\text { Surges }\end{array}$ & \\
\hline $\begin{array}{l}220 \mathrm{kV} \\
\text { Double } \\
\text { Circuit }\end{array}$ & 32 & 25.9 & 28.2 & 40 \\
\hline $\begin{array}{l}132 \mathrm{kV} \\
\text { Double } \\
\text { Circuit }\end{array}$ & 26.6 & 19.7 & 19.5 & 35 \\
\hline $\begin{array}{c}33 \mathrm{kV} \\
\text { Double } \\
\text { Circuit }\end{array}$ & 6.7 & 10.7 & 10 & 15 \\
\hline $\begin{array}{c}33 \mathrm{kV} \\
\text { Horizon } \\
\text { tal }\end{array}$ & 4.0 & 6 & 6.1 & 10 \\
\hline $\begin{array}{c}33 \mathrm{kV} \\
\text { Triangu } \\
\text { lar }\end{array}$ & 7.0 & 6.9 & 10.6 & 15 \\
\hline
\end{tabular}

No significant induced current (not at least in the range of $\mathrm{mA}$ ) is observed on the conductors in the presence of electric fields. Hence, it could be concluded that the minimum energy threshold for ignition of commercial electro 
explosive devices is not met due to the electric fields in free space under transmission lines.

However, the magnetic fields induced around transmission lines due to nominal rated loads, infrequent high loads, emergency short term loads, fault currents and currents due to travelling lightning surges could be significant enough to induce currents in the detonator circuits to meet the minimum energy threshold for ignition of EEDs. Therefore, detonators should not be used in explosive blasting within unsafe regions under transmission lines.

The following safe distance levels in Table 4 are proposed for safe operations of electro explosive devices.

Active or passive shielding of $50 \mathrm{~Hz}$ magnetic fields are to be used during the circuit connection procedure if detonator circuits are to be used inside the unsafe regions. If there is a mandatory requirement of rock blasting within the unsafe distances from transmission lines, use of normal detonators could be employed as an alternative.

Table 4 - Statement of Safe Distances for the Operation of Electrical Detonators

\begin{tabular}{|l|l|c|}
\hline Voltage & $\begin{array}{l}\text { Circuit } \\
\text { Configuration }\end{array}$ & $\begin{array}{l}\text { Safe Distance } \\
\text { from the line } \\
\text { center (m) }\end{array}$ \\
\hline $\mathbf{2 2 0} \mathbf{~ k V}$ & $\begin{array}{l}\text { Double Circuit } \\
\text { (twin conductor) }\end{array}$ & 40 \\
\hline $\mathbf{1 3 2} \mathbf{~ k V}$ & $\begin{array}{l}\text { Double Circuit } \\
\text { (twin conductor) }\end{array}$ & 35 \\
\hline $\mathbf{3 3} \mathbf{~ k V}$ & Double Circuit & 15 \\
\hline $\mathbf{3 3} \mathbf{~ k V}$ & Horizontal & 10 \\
\hline $\mathbf{3 3} \mathbf{~ k V}$ & Triangular & 15 \\
\hline
\end{tabular}

Switching off the transmission line is also an alternative but one has to keep in mind that the risk of travelling lightening waves is still a threat.

\section{References}

1. Kaune, W. T. and Zaffanella, L. E., "Analysis of Magnetic Fields Produced far from Electric Power Lines", IEEE Transactions on Power Delivery, 7(4) (1992), pp. 2082-2091.

2. Transmission Line Reference Book, Electrical Power Research Institute (EPRI) Publishers, $2005 \& 1992$.

3. Pramanik, A., Electromagnetism-Theory and Applications, Prentice Hall Publishers, India, 2004.

4. Hayt, W. H., Engineering Electromagnetics, Third Edition, Mc-Grow Hill Publishers, 2001.

5. Reale, D. V., Mankowski, J. and Dickens, J., "Susceptibility of Electro-Explosive Devices to High Pulsed Electric Fields", IEEE Transactions on Electro Magnetic Compatibility, (2012), pp. 211-214.

6. Lee K. R., Bennett J. E., Pinkston, W. H. and Bryant, J. E., "New Method of Assessing EED Susceptibility to Electromagnetic Radiation", IEEE Transactions on Electromagnetic Compatibility, 33(4) (1991), pp. 328-333.

7. Parson, J., Dickens, J., Walter, J. and Neuber, A. A., "Pulsed Magnetic Field Excitation Sensitivity of Match-type Electric Blasting Caps", IEEE Transactions on Electromagnetic Compatibility, 81 (2010), pp. 105-115.

8. Verakis, H. and Nicholas, D., Electric Blasting Systems Requirements for Shunting and Circuit Testing, Mine Safety and Health Administration, United States Department of Labour, November, 2006.

9. Begamure, R. D., Extra High Voltage AC Transmission Engineering, Second Edition, Wiley Eastern Limited, 1990.

10. Rodrigues, J. F., Creppe R. C., Porto, L. G. C., "How to Estimate the Electric Field Near Electric Energy Transmission Systems by Using Simple Software," Departamento de Engenharia Electrica, Faculdade de Engenharia, Bauru/UNESP, 2007.

11. Sligmann, P. C., "The Design of Circuits for Electrical Soft Firing," Journal of the South African Institute of Mining and Metallurgy, October 1978. 